\title{
Effects of Different Herbal Teas on Reducing the Bioaccessibility of Methylglyoxal in Crackers under Stimulated Gastrointestinal Digestive System
}

\author{
Elif Ede Çintesun $\left.{ }^{1,2} \mathbb{(}\right)$, Mustafa Yaman ${ }^{2, *(\mathbb{D})}$, Rabia Aslan $\left.{ }^{2} \mathbb{(}\right)$, Ömer Faruk Mizrak ${ }^{2} \mathbb{D}$, Sena Nur \\ Tanyildiz $^{2}$ (D), Hatice Yildirim ${ }^{2}$ (i), Rabia Bali ${ }^{2}$ (D), Büşranur Uçan ${ }^{2}$ (D) \\ 1 Istanbul Medipol University, Institue of Health Sciences, Department of Nutrition and Dietetics; \\ elifedecintesun@gmail.com (E.E.C.); \\ 2 Istanbul Sabahattin Zaim University, Faculty of Health Sciences, Department of Nutrition and Dietetics; \\ elif.ede@izu.edu.tr (E.E.C.), mustafayaman1977@gmail.com (M.Y.), dytrabiaslan@gmail.com (R.A.), \\ omer.mizrak@izu.edu.tr (O.F.M.), senanurtan@hotmail.com (S.N.T.), haticeyildirim96@hotmail.com (H.Y.), \\ rrabiabali@gmail.com (R.B.), busraucn@gmail.com (B.U.), \\ * Correspondence: mustafa.yaman@izu.edu.tr (M.Y.);
}

Received: 27.07.2021; Revised: 28.08.2021; Accepted: 29.08.2021; Published: 4.09.2021

\begin{abstract}
The present study aims to determine the bioaccessibility of methylglyoxal (MGO) in crackers and investigate the effects of herbal teas on reducing the formation of MGO under in vitro digestion system. Different herbal teas were added in crackers to reduce MGO formation under in vitro system. MGO levels were determined by High-Performance Liquid Chromatography. The amounts of MGO in crackers samples at initial and after in vitro digestion were ranged from 51 to $104 \mu \mathrm{g} / 100 \mathrm{~g}$ and 274 to $408 \mu \mathrm{g} / 100 \mathrm{~g}$, respectively. After in vitro digestion, the bioaccessibility of MGO values was increased up to $628 \%$. Also, it was found that polyphenol-rich herbal teas such as black, green, turmeric, and rosehip significantly reduced MGO bioaccessibility in crackers. The addition of these herbal teas as antioxidants in cracker formulations or consumption of herbal teas along with snack foods may be recommended.
\end{abstract}

Keywords: food processing; advanced glycation end products; methylglyoxal; crackers; bioaccessibility.

(c) 2021 by the authors. This article is an open-access article distributed under the terms and conditions of the Creative Commons Attribution (CC BY) license (https://creativecommons.org/licenses/by/4.0/).

\section{Introduction}

Processed foods are widely consumed in today's modern diet [1]. Food processing techniques can lead to the formation of $\alpha$-dicarbonyl compounds $(\alpha$-DC) in processed foods due to high-temperature processes, nutrition composition, low moisture, and $\mathrm{pH}$ [2]. $\alpha$-DC such as glyoxal (GO), and methylglyoxal (MGO) can be derived from Maillard reaction, caramelization, sugar autoxidation, and lipid peroxidation. The pathway through which $\alpha$-DC are produced depends on food composition and processing conditions. Caramelization occurs over $120{ }^{\circ} \mathrm{C}$ or $\mathrm{pH}$ between 3-9, whereas Maillard reaction requires $50{ }^{\circ} \mathrm{C}$ and $\mathrm{pH}$ in the range of 4-7 [3]. Sugar autoxidation takes place under all conditions that are relevant for food processing, especially in alkaline $\mathrm{pH}$. Lipid peroxidation may contribute to $\alpha$-DC accumulation in foods due to storage and process conditions [4]. $\alpha$-DC compounds react with amino groups of proteins to form final advanced glycation end products(AGEs) and advanced lipoxidation end products (ALEs) [5]. The highly reactive AGEs and ALEs such as $\mathrm{N}$ - $\varepsilon$-carboxymethyl 
lysine (CML) and N-e-carboxyethyllysine (CEL) are formed by the reaction of $\alpha$-DCs with the lysine group of amino acids, respectively [6].

AGEs are heterogeneous groups of molecules that can be formed endogenously or exogenously. The formation and accumulation of AGEs in the human body disrupt cell structure and functions, which causes oxidative stress and inflammation. AGEs play a direct role in developing age-related chronic degenerative diseases, diabetes mellitus, cardiovascular diseases, cancer, and central nervous system disorders [7]. Similar to AGEs, ALEs can be produced from $\alpha$-DCs. ALEs are lipid peroxidation products formed due to interaction between oxygen-derived free radicals and polyunsaturated fatty acids [8]. Lipid peroxidation is a serious problem in the food industry because it degrades food quality, alters texture properties, and reduces shelf life. Besides, lipid peroxidation causes inflammation in the human body. This increases the risk of atherosclerosis, age-related chronic conditions, cancer, and neurodegenerative disease. Considering all these adverse effects, it is important to prevent lipid peroxidation formation in foods. Lipid peroxidation is induced by exogen and endogen factors such as enzymes, heat, metal ions, radical species, and reactive oxygen species [9]. Food fat composition is also one of the most important determinants, especially polyunsaturated fats are at greater risk for lipid peroxidation than saturated fats [10]. Apart from these, the oxidation process of lipids increases under gastric digestion due to prooxidant conditions in the gastrointestinal tract such as low $\mathrm{pH}$ of gastric juice, presence of oxygen incorporated into food during mastication, and metallic ions [11]. Since digestion is dynamic, AGEs formation reactions or lipid peroxidation may increase or decrease digestive tract conditions [12]. Therefore it is important to know MGO formation in vitro.

Current strategies for reducing lipid peroxidation include changing processing conditions, reducing total fat or increasing saturated fat temperature, modifying packaging, coating foods to reduce oxygen exposure, and adding antioxidants [13]. Antioxidants are compounds capable of inhibiting or delaying oxidation by scavenging free radicals and preventing radical chain reactions [14]. Phenolic antioxidants inhibit lipid peroxidation by binding these lipid alkoxyl radicals [15].

Crackers are one of the most preferred processed snacks food, with major ingredients such as flour, fat, and salt. However, crackers are convenient for $\alpha$-DC formation due to low moisture, lipid oxidation, and sugar autoxidation [16]. There is limited study about the formation of lipid peroxidation products such as malondialdehyde (MDA), 4-hydroxy-2hexenal (HHE), and 4-hydroxy-2-nonenal (HNE) under in vitro gastrointestinal conditions, however, there is no study about the formation of $\alpha$-DC in the gastrointestinal system [11]. The present study aims to determine the formation of the MGO, which is one of the most potent precursors of AGEs in crackers, and investigate the effects of herbal teas on reducing the formation of MGO under in vitro gastrointestinal system conditions.

\section{Materials and Methods}

\subsection{Samples.}

In this research, four different polyphenol-rich herbal teas, including Camellia sinensis (black tea and green tea), Curcuma longa (turmeric), Rosa canina L. (rosehip) teas, and five different cracker samples were obtained local market in Istanbul, Turkey. Sample type and main contents of tea samples and crackers are shown in Table 1. 


\subsection{Materials.}

Methylglyoxal (40\%), methanol, acetonitrile, $\mathrm{KCl}, \mathrm{NaCl}, \mathrm{CaCl} 2.2 \mathrm{H} 2 \mathrm{O}, \mathrm{NaHCO} 3$, pepsin (porcine gastric mucosa, $\geq 250$ units/mg solid), alpha-amylase (Aspergillus oryzae, 1.5 $\mathrm{U} / \mathrm{mg}$ ), pancreatin (porcine pancreas, $8 \times \mathrm{USP}$ ), lipase (porcine pancreas, 100-500 units/mg protein), bovine serum, mucin, urea albumin, bile salts, uric acid were obtained from SigmaAldrich (St. Louis, MO, U.S.A).

In this study, the bioaccessibility of MGO in crackers samples was studied using in vitro stimulated human digestive system. The present in vitro system consisted of the stomach, mouth, and small intestinal medium [17].

Saliva: $16 \mathrm{~mL}$ urea $(2.5 \mathrm{~g} / 100 \mathrm{~mL}), 30 \mathrm{mg}$ uric acid, $3.4 \mathrm{~mL} \mathrm{NaCl}(17.5 \mathrm{~g} / 100 \mathrm{~mL})$, $560 \mathrm{mg} \alpha$-amylase, and $50 \mathrm{mg}$ mucin were dissolved in $1000 \mathrm{~mL}$ volumetric flask using deionized water. The final volume (adjusted $\mathrm{pH}$ 6.8) was completed with deionized.

Gastric juice: $36 \mathrm{~mL}$ of $\mathrm{CaCl}_{2} \cdot \mathrm{H}_{2} \mathrm{O}(2.22 \mathrm{~g} / 100 \mathrm{~mL}), 13 \mathrm{~mL}$ of $\mathrm{HCl}(37 \mathrm{~g} / \mathrm{L}), 2 \mathrm{~g}$ of bovine serum albumin, $5 \mathrm{~g}$ pepsin, and $6 \mathrm{~g}$ mucin was dissolved in $1000 \mathrm{~mL}$ volumetric flask using deionized water. The final volume (adjusted $\mathrm{pH} 1.5$ ) was completed with deionized water.

Duodenal juice: $18 \mathrm{~mL}$ of $\mathrm{CaCl}_{2} \cdot 2 \mathrm{H}_{2} \mathrm{O}(2.22 \mathrm{~g} / 100 \mathrm{~mL}), 12.6 \mathrm{~mL}$ of $\mathrm{KCl}(9.0 \mathrm{~g} / 100$ $\mathrm{mL}), 4 \mathrm{~g}$ bovine serum albumin, $18 \mathrm{~g}$ pancreatin, and also $3 \mathrm{~g}$ lipase was dissolved in $1000 \mathrm{~mL}$ volumetric flask, and the volume completed with deionized water. The final $\mathrm{pH}$ adjusted to 8.0.

Bile juice: $20 \mathrm{~mL}$ of $\mathrm{CaCl}_{2} \cdot 2 \mathrm{H}_{2} \mathrm{O}(2.2 \mathrm{~g} / 100 \mathrm{~mL}), 136.6 \mathrm{~mL}$ of $\mathrm{NaHCO}_{3}(17 \mathrm{~g} / 200$ $\mathrm{mL}), 3.6 \mathrm{~g}$ bovine serum albumin, and $60 \mathrm{~g}$ bile was dissolved in $1000 \mathrm{~mL}$ volumetric flask using deionized water. The final volume was completed and adjusted $\mathrm{pH}$ 7.0.2.3.

\subsection{In vitro digestion procedure.}

In this study, to determine the most effective tea concentration, 2, 4, and $6 \mathrm{ml}$ of each tea sample were added to cracker number 1 . Then, the effective tea concentration was added to each cracker sample in the simulated digestive systems. The teas were prepared as indicated on the label as follows one the bag $(2 \mathrm{~g})$ was brewed in $200 \mathrm{ml}$ water at $100^{\circ} \mathrm{C}$ for $5 \mathrm{~min}$. Then, it cooled down to $37^{\circ} \mathrm{C}$ for in vitro digestion. One portion of medium cracker and one portion of tea are $50 \mathrm{~g}$ and $200 \mathrm{~mL}$, respectively indicated on the labels.

The bioaccessibility of the GO and MGO in cookies was determined using an in vitro simulated human digestive system. This in vitro simulated method was a modified version of that described previously by Yaman et al. (2019) [17]. Saliva, gastric, duodenal, and bile juices were prepared as $1000 \mathrm{~mL}$ and shown in Figure 1.
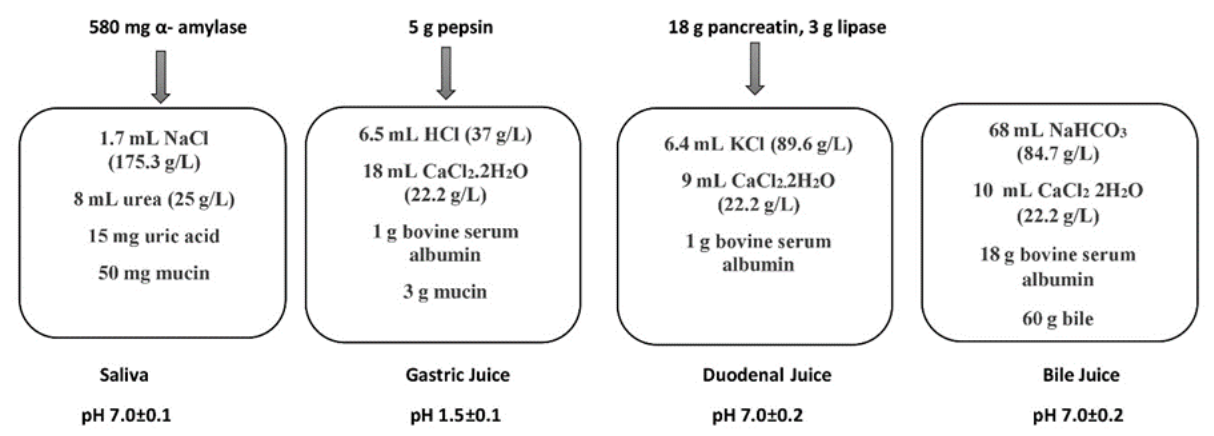

Figure 1. Saliva, gastric, duodenal, and bile juices used in the in vitro human digestion model. 
$1.5 \mathrm{~g}$ of each cracker test sample with herbal teas were mixed with $5 \mathrm{~mL}$ of saliva solution in a $100 \mathrm{~mL}$ beaker and incubated for $5 \mathrm{~min}$ at $37^{\circ} \mathrm{C}$ in a shaking water bath. Then, $12 \mathrm{~mL}$ of gastric juice were added to the fluid obtained from the mouth phase and incubated for $1 \mathrm{~h}$ at $37{ }^{\circ} \mathrm{C}$ in a shaking water bath. After that, $5 \mathrm{~mL}$ of bile juice and $10 \mathrm{~mL}$ of duodenal juice were added to the sample obtained from the gastric phase. Then, this mixture was incubated for $2 \mathrm{~h}$ at $37^{\circ} \mathrm{C}$ in a shaking water bath. After that, the final volume was diluted with deionized water to $50 \mathrm{~mL}$. The samples were then centrifuged for $5 \mathrm{~min}$ at $8000 \mathrm{xg}$ and filtered through a filter paper. This solution was used for the analysis of MGO. Bioaccessibility was calculated by dividing the concentration of $\mathrm{v}$ MGO in the digest by the MGO concentration in the original nondigested sample and expressed as a percentage.

\subsection{HPLC determination of $M G O$.}

The HPLC conditions for the determination of MGO described by Cengiz et al. (2020) were used. The HPLC system consisted of a Shimadzu LC 20AT pump with a Shimadzu SPD20A UV/VIS detector (Shimadzu Corporation, Kyoto, Japan). The mobile phase has consisted of MeOH:water:ACN (42:56:2 v/v/v). The wavelength was set to $254 \mathrm{~nm}$. An Inersil ODS-3 column was used with a flow rate of $1 \mathrm{~mL} / \mathrm{min}$, and the column oven temperature was set $30^{\circ} \mathrm{C}$.

\subsection{Statistical analysis.}

The average value $(\mathrm{n}=3)$ was given with a standard deviation. Significant differences were determined using ANOVA Tukey's test $(\mathrm{p}<0.05)$.

\section{Results and Discussion}

The HPLC chromatogram of MGO in cracker 1 is shown in Figure 2.

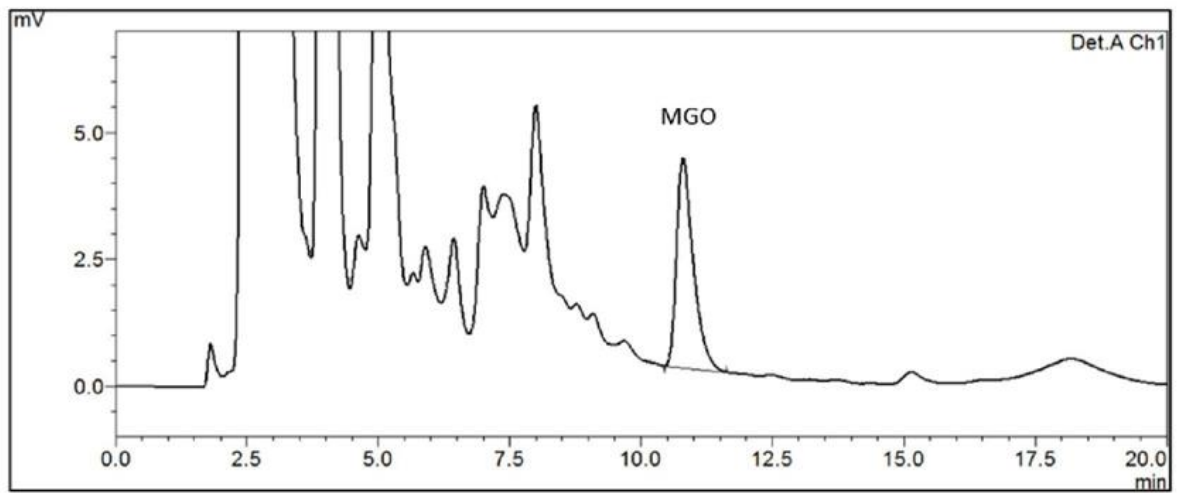

Figure 2 HPLC chromatogram of MGO in cracker 1.

The declared amount of macronutrients in cracker samples are given in Table 1.

As presented in Table 2, the amount of MGO in cracker and tea samples ranged between 51 and $104 \mu \mathrm{g} / 100 \mathrm{~g}$, and 10 and $16.6 \mu \mathrm{g} / 100 \mathrm{~g}$, respectively. The highest MGO value was observed in cracker 4 and cracker 5 samples. However, MGO values were found very low $(<17$ $\mu / 100 \mathrm{ml}$ ) in tea samples compared to crackers. The amounts of MGO in crackers and tea samples after in vitro gastrointestinal digestion were ranged from 274 to $408 \mu \mathrm{g} / 100 \mathrm{~g}$ and 10 to $16.9 \mu \mathrm{g} / 100 \mathrm{~g}$, respectively. As seen, the MGO amounts in cracker samples were increased compared to initial values, and the increase rate was between 266 and $628 \%$. Whereas the MGO amounts in tea samples were not increased compared to initial values $(\mathrm{p}>0.05)$. 
Table 1. The declared amount of carbohydrate, sugar, protein, fat, fiber and salt in cracker samples.

\begin{tabular}{l|c|c|c|c|c|c|c|c} 
Sample no & $\begin{array}{c}\text { Energy } \\
(\mathbf{k c a l})\end{array}$ & $\begin{array}{c}\text { Carb } \\
(\mathbf{g} / \mathbf{1 0 0 g})\end{array}$ & $\begin{array}{c}\text { Protein } \\
(\mathbf{g} / \mathbf{1 0 0 g})\end{array}$ & $\begin{array}{c}\text { Fat } \\
(\mathbf{g} / \mathbf{1 0 0 g})\end{array}$ & $\begin{array}{c}\text { Saturated Fat } \\
(\mathbf{g} / \mathbf{1 0 0 g})\end{array}$ & $\begin{array}{c}\text { Sugar } \\
(\mathbf{g} / \mathbf{1 0 0 g})\end{array}$ & $\begin{array}{c}\text { Fiber } \\
(\mathbf{g} / \mathbf{1 0 0 g})\end{array}$ & $\begin{array}{c}\text { Salt } \\
(\mathbf{g} / \mathbf{1 0 0 g})\end{array}$ \\
\hline Cracker 1, cheese & 468 & 65.0 & 8.9 & 19.0 & 8.7 & 8.1 & 2.7 & 2.4 \\
\hline Cracker 2, spicy & 413 & 71 & 8.5 & 13.3 & 6.8 & 7.6 & 3.1 & 2.8 \\
\hline Cracker 3, hot spicy & 457 & 57.1 & 7.9 & 21.9 & 11.2 & 7.6 & 3.4 & 2.7 \\
\hline Cracker 4, plain & 400 & 75.3 & 10 & 5.9 & 2.7 & 0 & 3.2 & 4.8 \\
\hline Cracker 5, sesame & 463 & 61 & 10 & 19 & 7.3 & 6.3 & 4.9 & 1.8
\end{tabular}

As seen from Table 1, cracker samples contain a high amount of carbohydrate and fat and ranged from 57.1 to 75.3 and 5.9 to $21.9 \mathrm{~g} / 100 \mathrm{~g}$, respectively. The measured amount of MGO in crackers and teas is presented in Table 2.

Table 2. Sample type and main contents, amount of MGO before and after digestion, and increase rate.

\begin{tabular}{l|c|c|c|c} 
Sample no & $\begin{array}{c}\text { Sample type and main } \\
\text { contents }\end{array}$ & $\begin{array}{c}\text { Initial value } \\
\text { MGO }(\boldsymbol{\mu g} / \mathbf{1 0 0} \mathbf{g})\end{array}$ & $\begin{array}{c}\text { After Digestion } \\
\mathbf{M G O}(\boldsymbol{\mu g} / \mathbf{1 0 0} \mathbf{g})\end{array}$ & Increase Rate \% \\
\hline Cracker 1 & Cracker, cheese & $97 \pm 4$ & $408 \pm 18$ & $424 \pm 19$ \\
\hline Cracker 2 & Cracker, spicy & $51 \pm 2$ & $312 \pm 14$ & $617 \pm 28$ \\
\hline Cracker 3 & Cracker, hot spicy & $57 \pm 3$ & $355 \pm 16$ & $628 \pm 29$ \\
\hline Cracker 4 & Cracker, plain & $102 \pm 5$ & $299 \pm 14$ & $296 \pm 13$ \\
\hline Cracker 5 & Cracker, sesame & $104 \pm 5$ & $274 \pm 12$ & $266 \pm 12$ \\
\hline Tea 1 & Tea, black & $14 \pm 1$ & $15 \pm 1$ & $107 \pm 4$ \\
\hline Tea 2 & Tea, green & $10 \pm 0$ & $10 \pm 1$ & $100 \pm 3$ \\
\hline Tea 3 & Tea, turmeric & $17 \pm 1$ & $17 \pm 1$ & $103 \pm 4$ \\
\hline Tea 4 & Tea, rosehip & $14 \pm 1$ & $14 \pm 1$ & $100 \pm 3$
\end{tabular}

Crackers are prone to $\alpha$-DC formation due to rich carbohydrate, fat content, low moisture, and high-temperature cooking conditions [18]. Cengiz et al. measured MGO levels in crackers between 123-661 $\mu \mathrm{g} / 100 \mathrm{~g}$ [19]. Similar to Cengiz et al., in the present study high amount of MGO was detected in crackers. Differences in the amount of MGO between cracker samples may be attributed to shelf life and storage conditions. Carbohydrate content may contribute to MGO formation by sugar autoxidation or Maillard reaction [16]. Besides, lipid peroxidation can cause MGO formation in crackers. Unsaturated fats are at greater risk for lipid oxidation than saturated fats [20]. As seen in Table 1, all cracker samples contain about 50\% unsaturated fat of total fat. This may have caused increased MGO formation in crackers. Lipid peroxidation increase with digestion due to prooxidant conditions in the gastrointestinal tract [11]. Therefore, MGO content was analyzed in crackers under in vitro gastrointestinal conditions, and as seen in Table 2 it was observed that MGO content increased up to 6 fold. The bioaccessibility of MGO was also studied by different researchers. Lugt et al. found that the presence of methylglyoxal-derived hydroimidazolone-1 in the gastrointestinal tract increased by more than $400 \%$ in ginger biscuits [21]. On the contrary, Degen et al. found that, After 8 hours of in vitro digestion, only 5-20\% of the initial methylglyoxal was recovered in Manuka honey [22]. Daglia et al. also observed that after digestion, MGO concentration decreases in Manuka honey because MGO reacts with digestive enzymes by carbonylation their free amino groups [23]. The differences between results may be attributed to food composition or food processing techniques. In vitro, simulated digestion can reduce or strongly increase free $\alpha$-DCs content depend on food content or reactions occurring during digestion [24].

Lipid peroxidation causes unfavorable effects on shelf life, nutrition quality, texture, storage time in foods and leads to the formation of ALEs in the body; therefore, it is important to reduce lipid peroxidation in foods $[25,26]$. Antioxidants slow or prevent lipid oxidations in foods by scavenging free radicals, inactivating lipoxygenase, quenching singlet oxygen, and 
chelating pro-oxidative metals [27]. Phenolic compounds have high antioxidant properties and prevent lipid oxidation through various mechanisms [28]. For this purpose, some herbal teas were added to crackers to reduce MGO content. Teas were also analyzed to evaluate the possible interactions between MGO content in teas and crackers. It was observed that the amount of MGO in the teas was low, and these amounts were not affected by in vitro gastrointestinal system conditions (Table 2). It was ensured that tea treatment would not affect MGO content in crackers. Bioaccessibility of MGO in cracker sample after different concentration tea samples are given in Table 3.

Table 3. Bioaccessibility of MGO in cracker sample after different concentration tea samples.

\begin{tabular}{l|c|c|c|c|c|c|c|c|c}
\multirow{2}{*}{$\begin{array}{l}\text { Sample } \\
\text { Name }\end{array}$} & \multicolumn{3}{|c|}{$\begin{array}{c}\text { After Digestion } \text { MGO }^{\mathbf{1}} \\
(\boldsymbol{\mu g} / \mathbf{1 0 0} \mathbf{g})\end{array}$} & \multicolumn{2}{c|}{$\begin{array}{c}\text { MGO increase rate compared to } \\
\text { initial value \% }\end{array}$} & \multicolumn{2}{c}{ Reducing Rate \% } \\
\cline { 2 - 11 } & $2 \mathrm{ml}$ & $4 \mathrm{ml}$ & $6 \mathrm{ml}$ & $2 \mathrm{ml}$ & $4 \mathrm{ml}$ & $6 \mathrm{ml}$ & $2 \mathrm{ml}$ & $4 \mathrm{ml}$ & $6 \mathrm{ml}$ \\
\hline Cracker 1+ Tea 1 & $291 \pm 10^{\mathrm{a}}$ & $244 \pm 9^{\mathrm{b}}$ & $215 \pm 8^{\mathrm{c}}$ & $300 \pm 11$ & $251 \pm 9$ & $222 \pm 8$ & $29 \pm 2$ & $40 \pm 2$ & $47 \pm 2$ \\
\hline Cracker 1+ Tea 2 & $288 \pm 10^{\mathrm{a}}$ & $193 \pm 7^{\mathrm{b}}$ & $149 \pm 5^{\mathrm{c}}$ & $297 \pm 10$ & $199 \pm 7$ & $154 \pm 5$ & $30 \pm 2$ & $53 \pm 2$ & $64 \pm 1$ \\
\hline Cracker 1+ Tea 3 & $323 \pm 11^{\mathrm{a}}$ & $269 \pm 9^{\mathrm{b}}$ & $260 \pm 9^{\mathrm{b}}$ & $333 \pm 12$ & $278 \pm 10$ & $268 \pm 9$ & $21 \pm 3$ & $34 \pm 2$ & $36 \pm 2$ \\
\hline Cracker 1+ Tea 4 & $274 \pm 10^{\mathrm{a}}$ & $272 \pm 10^{\mathrm{a}}$ & $258 \pm 9^{\mathrm{a}}$ & $283 \pm 10$ & $281 \pm 10$ & $266 \pm 9$ & $33 \pm 2$ & $33 \pm 2$ & $37 \pm 2$
\end{tabular}

Values refer to the mean \pm standard deviation $(n=3)$ for quantification of MGO in the reference material (cracker samples). ${ }^{1}$ The different letters in the same row indicate that there are statistical differences between the applications (ANOVA $\mathrm{p}<0.05$, Tukey's test).

As seen from table 3, 4 four different tea samples with 3 different concentrations $(2,4$, and $6 \mathrm{~mL}$ ) were treated to cracker 1 (Table 2) in the simulated gastrointestinal system. When crakcer1 was treated with different concentrations of tea samples, the increase rate of MGO (424\%) was reduced by all tea samples with different concentrations. The highest decrease was observed for $6 \mathrm{ml}$ of tea treatments, and the increase rate of MGO was decreased between 154 and $268 \%$. The addition of tea 1 , tea 2 , tea 3 , and tea 4 samples to cracker 1 reduced the initial MGO value by $47,64,36$, and $37 \%$, in the simulated gastrointestinal system, respectively. Surprisingly, it was seen that $6 \mathrm{ml}$ of tea added to the cracker corresponded to 1 portion of tea. In this regard, the optimal ratio was found in 1 portion. Therefore, in this study, the amount of tea added to crackers was accepted as $6 \mathrm{ml}$ in other cracker samples.

As in the cracker 1 sample, the crackers 2, 3, 4, and 5 samples were treated with the tea samples. The amount of MGO in cracker 2, cracker 3, cracker 4, and cracker 5 was reduced by tea samples from 31 to $53 \%, 52$ to $60 \%, 55$ to $80 \%$, and 21 to $80 \%$, respectively (Table 4). It was observed that in this study, the most effective teas in reducing the amount of MGO were green tea for cracker 1 and cracker 2, rosehip tea for cracker 3, turmeric for cracker 4, and black tea for cracker 5 . Generally, the reducing rate in cracker samples was between 31 and $81 \%$.

Table 4. Bioaccessibility of MGO in cracker samples after tea treatments.

\begin{tabular}{|c|c|c|c|c|c|c|c|c|c|c|c|c|}
\hline \multirow[t]{2}{*}{ Sample no } & \multicolumn{4}{|c|}{$\begin{array}{c}\text { After Digestion } \text { MGO}^{1} \\
(\mu \mathrm{g} / 100 \mathrm{~g})\end{array}$} & \multicolumn{4}{|c|}{ MGO increase rate (\%) } & \multicolumn{4}{|c|}{ Reducing Rate \% } \\
\hline & Tea 1 & Tea 2 & Tea 3 & Tea 4 & Tea 1 & Tea 2 & Tea 3 & Tea 4 & Tea 1 & Tea 2 & Tea 3 & Tea 4 \\
\hline Cracker 2 & $160 \pm 7^{\mathrm{a}}$ & $147 \pm 7^{\mathrm{a}}$ & $217 \pm 10^{\mathrm{b}}$ & $164 \pm 7^{\mathrm{a}}$ & $313 \pm 14$ & $287 \pm 13$ & $426 \pm 19$ & $321 \pm 15$ & $49 \pm 2$ & $53 \pm 2$ & $31 \pm 3$ & $48 \pm 2$ \\
\hline Cracker 3 & $153 \pm 7^{\mathrm{a}}$ & $171 \pm 8^{\mathrm{b}}$ & $170 \pm 8^{\mathrm{b}}$ & $143 \pm 6^{\mathrm{a}}$ & $269 \pm 12$ & $301 \pm 14$ & $299 \pm 14$ & $250 \pm 11$ & $57 \pm 2$ & $52 \pm 2$ & $52 \pm 2$ & $60 \pm 2$ \\
\hline Cracker 4 & $90 \pm 4^{\mathrm{a}}$ & $136 \pm 6^{b}$ & $58 \pm 3^{c}$ & $104 \pm 5^{d}$ & $89 \pm 4$ & $134 \pm 6$ & $57 \pm 3$ & $102 \pm 5$ & $70 \pm 1$ & $55 \pm 2$ & $81 \pm 1$ & $65 \pm 2$ \\
\hline Cracker 5 & $54 \pm 2^{\mathrm{a}}$ & $128 \pm 6^{\mathrm{b}}$ & $217 \pm 10^{c}$ & $64 \pm 3^{\mathrm{d}}$ & $52 \pm 2$ & $123 \pm 6$ & $209 \pm 9$ & $62 \pm 3$ & $80 \pm 1$ & $54 \pm 2$ & $21 \pm 4$ & $77 \pm 1$ \\
\hline
\end{tabular}

It is known that phenolic antioxidants reduce lipid peroxidation in foods. Lin et al. indicated in their study that green tea extract inhibits lipid peroxidation in pepperoni during 
storage [29]. Khennouf et al. determined that phenolic compounds reduce lipid peroxidation by \%42-51 [30]. Lorrain et al. showed that polyphenols inhibit lipid oxidation under gastric conditions [31]. In line with these studies, it was observed that green tea and black tea with phenolic properties reduce the amount of MGO up to \%80, which is the potent lipid peroxidation precursor.

Turmeric has high antioxidant properties due to the phenolic components it contains. Therefore, it can be used in foods to prevent lipid oxidation. Kanani et al. showed that turmeric supplementation in heat-treated chickens significantly decreased the level of thiobarbituric acid (TBAR), which is a precursor of lipid peroxidation [32]. Van Hecke et al. tested the potential of herbs and spices to reduce lipid oxidation during gastrointestinal digestion in beef products. They found that turmeric was the most effective herb for reducing lipid peroxidation under gastrointestinal digestion [33]. The effects of turmeric on lowering lipid peroxidation had generally been studied on meats, but there is a need for studies focused on low moisture foods such as crackers. In this study, results showed that turmeric reduces MGO amount up to \%81 in crackers under gastrointestinal conditions. D'souza et al. investigated the effects of turmeric on reducing MDA levels in fish. They found turmeric exhibited a significant reduction in lipid peroxides up to $\% 28$ [34].

Rosehip's potential to reduce lipid peroxidation has also been studied, but these studies have also been conducted on animal foods and have not been studied on low moisture foods. According to Özer, rosehip can be used in fermented meat products to inhibit lipid oxidation [35]. Varzaru et al. investigated the effects of rosehip on reducing lipid peroxidation in eggs. For this purpose, a rosehip supplement was given to laying hens. They found that rosehip supplementation reduced lipid peroxidation by up to $25 \%$ compared to control groups [36]. Similarly, in the present study, it was found that rosehip tea reduces MGO levels, these results also show that it has a lowering effect under the gastrointestinal system.

Prevention of lipid peroxidation in foods is crucial for both the food industry and human health. Inhibition of lipid peroxidation with antioxidants had been widely studied. These studies had been mostly focused on meat products. However, lipid peroxidation in low moisture foods is a serious problem due to their polyunsaturated fat content, but this issue has been poorly studied. In addition, most of the studies evaluate lipid peroxidation with MDA or TBAR. $\alpha$-DC compounds are potential ALEs precursors that can be formed through lipid peroxidation. Therefore MGO analysis can be used as a precursor to evaluating lipid peroxidation. Moreover, lipid peroxidation increases with digestion; for this reason, it is important to evaluate MGO levels under gastrointestinal conditions. This study has a unique value in terms of investigating the effects of herbal teas on reducing MGO as a potential lipid peroxidation product under gastrointestinal conditions in low moisture foods. Findings showed that herbal teas significantly reduced MGO formation in crackers. The addition of these herbal teas as antioxidants in cracker formulations or consumption of herbal teas and low moisture foods may be recommended.

\section{Conclusions}

Briefly, in this study, it was demonstrated that MGO formation increases with digestion. For this reason, it is important to evaluate MGO levels under gastrointestinal conditions. The present study was also demonstrated that polyphenol-rich herbal teas significantly reduced MGO formation in crackers in the gastrointestinal systems. , The addition of these herbal teas as antioxidants in cracker formulations or consumption of herbal teas along with snack foods 
may be recommended since this study had revealed that MGO in crackers under in vitro conditions, further studies are needed to investigate $\alpha$-DCs formation in such foods extensively.

\section{Funding}

This research received no external funding.

\section{Acknowledgments}

We would like to thank Istanbul Sabahattin Zaim University for their support.

\section{Conflicts of Interest}

The authors declare no conflict of interest.

\section{References}

1. Juul, F.; Martinez-Steele, E.; Parekh, N.; Monteiro, C.A.; Chang, V.W. Ultra-processed food consumption and excess weight among US adults. British Journal of Nutrition 2018, 120, 90-100, https://doi.org/10.1017/S0007114518001046.

2. Zhuang, Y.; Dong, L.; Wang, J.-P.; Wang, S.-J.; Wang, S. Formation and migration of $\alpha$-dicarbonyl compounds during storage and reheating of a sugary food simulation system. Journal of the Science of Food and Agriculture 2020, 100, 2296-2304, https://doi.org/10.1002/jsfa.10263.

3. Shen, C.-Y.; Lu, C.-H.; Wu, C.-H.; Li, K.-J.; Kuo, Y.-M.; Hsieh, S.-C.; Yu, C.-L. The Development of Maillard Reaction, and Advanced Glycation End Product (AGE)-Receptor for AGE (RAGE) Signaling Inhibitors as Novel Therapeutic Strategies for Patients with AGE-Related Diseases. Molecules 2020, 25, https://doi.org/10.3390/molecules25235591.

4. Wang, S. Chemical Hazards in Thermally-Processed Foods $1^{\text {st }}$ ed.; Singapore, Springer, 2019; pp. 19-47.

5. Perrone, A.; Giovino, A.; Benny, J.; Martinelli, F. Advanced Glycation End Products (AGEs): Biochemistry, Signaling, Analytical Methods, and Epigenetic Effects. Oxidative Medicine and Cellular Longevity 2020, 2020, https://doi.org/10.1155/2020/3818196.

6. Moldogazieva, N.T.; Mokhosoev, I.M.; Mel'nikova, T.I.; Porozov, Y.B.; Terentiev, A.A. Oxidative Stress and Advanced Lipoxidation and Glycation End Products (ALEs and AGEs) in Aging and Age-Related Diseases. Oxidative Medicine and Cellular Longevity 2019, 2019, https://doi.org/10.1155/2019/3085756.

7. Nowotny, K.; Schröter, D.; Schreiner, M.; Grune, T. Dietary advanced glycation end products and their relevance for human health. Ageing Research Reviews 2018, 47, 55-66, https://doi.org/10.1016/j.arr.2018.06.005.

8. Mol, M.; Degani, G.; Coppa, C.; Baron, G.; Popolo, L.; Carini, M.; Aldini, G.; Vistoli, G.; Altomare, A. Advanced lipoxidation end products (ALEs) as RAGE binders: Mass spectrometric and computational studies to explain the reasons why. Redox Biology 2019, 23, https://doi.org/10.1016/j.redox.2018.101083.

9. Vu, T.P.; He, L.; McClements, D.J.; Decker, E.A. Effects of water activity, sugars, and proteins on lipid oxidative stability of low moisture model crackers. Food Research International 2020, 130, https://doi.org/10.1016/j.foodres.2019.108844.

10. Gumus, C.E.; Decker, E.A. Oxidation in Low Moisture Foods as a Function of Surface Lipids and Fat Content. Foods 2021, 10, https://doi.org/10.3390/foods10040860.

11. Nieva-Echevarría, B.; Goicoechea, E.; Guillén, M.D. Food lipid oxidation under gastrointestinal digestion conditions: A review. Crit Rev Food Sci Nutr 2020, 60, 461-478, https://doi.org/10.1080/10408398.2018.1538931.

12. Zheng, J.; Guo, H.; Ou, J.; Liu, P.; Huang, C.; Wang, M.; Simal-Gandara, J.; Battino, M.; Jafari, S.M.; Zou, L.; Ou, S.; Xiao, J. Benefits, deleterious effects and mitigation of methylglyoxal in foods: A critical review. Trends in Food Science \& Technology 2021, 107, 201-212, https://doi.org/10.1016/j.tifs.2020.10.031.

13. Jackson, V.; Penumetcha, M. Dietary oxidised lipids, health consequences and novel food technologies that thwart food lipid oxidation: an update. International Journal of Food Science \& Technology 2019, 54, 19811988, https://doi.org/10.1111/ijfs.14058.

14. Yang, C.S.; Ho, C.-T.; Zhang, J.; Wan, X.; Zhang, K.; Lim, J. Antioxidants: Differing Meanings in Food Science and Health Science. Journal of Agricultural and Food Chemistry 2018, 66, 3063-3068, https://doi.org/10.1021/acs.jafc.7b05830.

15. Namal Senanayake, S.P.J. Green tea extract: Chemistry, antioxidant properties and food applications - A review. Journal of Functional Foods 2013, 5, 1529-1541, https://doi.org/10.1016/j.jff.2013.08.011.

16. Sykes, G.; Davidson, I. Biscuit, cookie and cracker process and recipes. Elsevier, 2020; pp. 1-31. 
17. Yaman, M.; Mizrak, Ö.F. Determination and evaluation of in vitro bioaccessibility of the pyridoxal, pyridoxine, and pyridoxamine forms of vitamin B6 in cereal-based baby foods. Food Chemistry 2019, 298, https://doi.org/10.1016/j.foodchem.2019.125042.

18. Uribarri, J.; Woodruff, S.; Goodman, S.; Cai, W.; Chen, X.; Pyzik, R.; Yong, A.; Striker, G.E.; Vlassara, H. Advanced Glycation End Products in Foods and a Practical Guide to Their Reduction in the Diet. Journal of the American Dietetic Association 2010, 110, 911-916, https://doi.org/10.1016/j.jada.2010.03.018.

19. Cengiz, S.; Kişmiroğlu, C.; Çebi, N.; Çatak, J.; Yaman, M. Determination of the most potent precursors of advanced glycation end products (AGEs) in chips, crackers, and breakfast cereals by high performance liquid chromatography (HPLC) using precolumn derivatization with 4-nitro-1,2-phenlenediamine. Microchemical Journal 2020, 158, https://doi.org/10.1016/j.microc.2020.105170.

20. Barden, L.; Vollmer, D.; Johnson, D.; Decker, E. Impact of Iron, Chelators, and Free Fatty Acids on Lipid Oxidation in Low-Moisture Crackers. Journal of Agricultural and Food Chemistry 2015, 63, 1812-1818, https://doi.org/10.1021/jf5048018.

21. van der Lugt, T.; Venema, K.; van Leeuwen, S.; Vrolijk, M.F.; Opperhuizen, A.; Bast, A. Gastrointestinal digestion of dietary advanced glycation endproducts using an in vitro model of the gastrointestinal tract (TIM1). Food \& Function 2020, 11, 6297-6307, https://doi.org/10.1039/d0fo00450b.

22. Degen, J.; Vogel, M.; Richter, D.; Hellwig, M.; Henle, T. Metabolic Transit of Dietary Methylglyoxal. Journal of Agricultural and Food Chemistry 2013, 61, 10253-10260, https://doi.org/10.1021/jf304946p.

23. Daglia, M.; Ferrari, D.; Collina, S.; Curti, V. Influence of in Vitro Simulated Gastroduodenal Digestion on Methylglyoxal Concentration of Manuka (Lectospermum scoparium) Honey. Journal of Agricultural and Food Chemistry 2013, 61, 2140-2145, https://doi.org/10.1021/jf304299d.

24. Hamzalığlu, A.; Gökmen, V. Potential reactions of thermal process contaminants during digestion. Trends in Food Science \& Technology 2020, 106, 198-208, https://doi.org/10.1016/j.tifs.2020.10.014.

25. Vistoli, G.; De Maddis, D.; Cipak, A.; Zarkovic, N.; Carini, M.; Aldini, G. Advanced glycoxidation and lipoxidation end products (AGEs and ALEs): an overview of their mechanisms of formation. Free Radical Research 2013, 47, 3-27, https://doi.org/10.3109/10715762.2013.815348.

26. Gebreselassie, E.; Clifford, H. Chapter 12 - Oxidative Stability and Shelf Life of Crackers, Cookies, and Biscuits. In: Oxidative Stability and Shelf Life of Foods Containing Oils and Fats. Hu, M.; Jacobsen, C. Eds.; AOCS Press: 2016; pp. 461-478, https://doi.org/10.1016/B978-1-63067-056-6.00012-4.

27. Choe, E.; Min, D.B. Mechanisms of Antioxidants in the Oxidation of Foods. Comprehensive Reviews in Food Science and Food Safety 2009, 8, 345-358, https://doi.org/10.1111/j.1541-4337.2009.00085.x.

28. Lorenzo, J.M.; Munekata, P.E.S. Phenolic compounds of green tea: Health benefits and technological application in food. Asian Pacific Journal of Tropical Biomedicine 2016, 6, 709-719, https://doi.org/10.1016/j.apjtb.2016.06.010.

29. Lin, Y.; Huang, M.; Zhou, G.; Zou, Y.; Xu, X. Prooxidant Effects of the Combination of Green Tea Extract and Sodium Nitrite for Accelerating Lipolysis and Lipid Oxidation in Pepperoni during Storage. Journal of Food Science 2011, 76, C694-C700, https://doi.org/10.1111/j.1750-3841.2011.02187.x.

30. Khennouf, S.; Amira, S.; Arrar, L.; Baghiani, A. Effect of some phenolic compounds and quercus tannins on lipid peroxidation. World Appl. Sci. J. 2010, 8, 1144-1149.

31. Lorrain, B.; Dangles, O.; Loonis, M.; Armand, M.; Dufour, C. Dietary Iron-Initiated Lipid Oxidation and Its Inhibition by Polyphenols in Gastric Conditions. Journal of Agricultural and Food Chemistry 2012, 60, 90749081, https://doi.org/10.1021/jf302348s.

32. Baghban Kanani, P.; Daneshyar, M.; Aliakbarlu, J.; Hamian, F. Effect of dietary turmeric and cinnamon powders on meat quality and lipid peroxidation of broiler chicken under heat stress condition. Vet Res Forum 2017, 8, 163-169.

33. Van Hecke, T.; Ho, P.L.; Goethals, S.; De Smet, S. The potential of herbs and spices to reduce lipid oxidation during heating and gastrointestinal digestion of a beef product. Food Research International 2017, 102, 785792, https://doi.org/10.1016/j.foodres.2017.09.090.

34. D'Souza, H.P.; Prabhu, H.R. In vitro inhibition of lipid peroxidation in fish by turmeric (Curcuma longa). Indian J Clin Biochem 2006, 21, 138-141, https://doi.org/10.1007/BF02912929.

35. Özer, C.O. Fermente Et Model Sistemi İçerisinde Kuşburnu (Rosa Canina L.) Meyvesi Kullanimi. Gıda 2017, 42, 372-381.

36. Varzaru, I.; Untea, A.E.; Panaite, T.; Olteanu, M. Effect of dietary phytochemicals from tomato peels and rosehip meal on the lipid peroxidation of eggs from laying hens. Archives of Animal Nutrition 2021, 75, 1830, https://doi.org/10.1080/1745039X.2020.1813515. 